\title{
Characteristics of Sensitization to Inhalant and Food Allergens
}

\author{
George Ch. Christoff ${ }^{1,2, *}$, Emilia G. Karova ${ }^{3}$ \\ ${ }^{1}$ Faculty of Public Health, Department of Health Economics, Medical University, Sofia, Bulgaria \\ ${ }^{2}$ Allergy outpatient clinic. Tokuda Medical Centre, Sofia, Bulgaria \\ ${ }^{3}$ Faculty of Dental Medicine, Department of Conservative Dentistry, Medical University, Sofia, Bulgaria \\ *Corresponding author: christoff_g@yahoo.com
}

Received April 28, 2014; Revised June 21, 2014; Accepted July 06, 2014

\begin{abstract}
Background: Many studies worldwide have reported prevalence of atopic sensitization and its international variations. A positive skin prick reaction, however, does not always correlate with clinical symptoms. Positive skin tests (SPT) reveal rather atopy - specific IgE presence, than an atopic disease itself. When combined clinical manifestation and SPT are a powerful instrument for defining allergic diseases. Such data for Bulgaria are, however, scarce. The objective of the present study is to assess prevalence patterns and clinical relevance of sensitization to environmental and food allergens in a cross-sectional community sample in Bulgaria. Methodology and results: Patients, 225 men and women, age 4-81 years, were included. They completed a questionnaire to define asthma and rhinitis. Patients were skin prick tested to 18 commercial inhalant and food allergen extracts. The clinical relevance of each of the positively tested allergens was assessed. Among 225 patients 129 (57.3\%) were sensitized to at least one allergen, using cut-off level $\geqslant 3 \mathrm{~mm}$. In the inhalant allergens group the highest were rates of sensitization to 12 grasses $-26.6 \%$ and 4 cereals $-24.0 \%$, followed by these to DFR $-18.2 \%$, DPT $-17.8 \%$ and cockroach $-16.4 \%$. Among food allergens the highest rates of sensitizations were found to pork $-16.9 \%$, walnut $15.1 \%$, apple $-13.3 \%$, egg whole $-10.7 \%$, celery $-9.8 \%$ and milk $-9.3 \%$. The highest proportions of relevant tests in the inhalant allergens group were for DPT - 72.2\%, DFR - 62.9\%, 4 cereals - 69.2\%, 12 grasses - 69\%, Penicillium mix -61.9 , cockroach - 54.8\%, Betulaceae - 52.4\%. Among food allergens the highest proportions of relevant sensitization were found for walnut $-32.3 \%$, peanut $29.4 \%$, Milk - $22.2 \%$, egg whole - $21.1 \%$. Conclusions: We found rates and patterns of sensitization which were in line with data from other studies. The percentage of clinically relevant sensitizations differed significantly depending on the allergen.
\end{abstract}

Keywords: prevalence, clinical relevance, sensitization, atopy, inhalant allergens, food allergens

Cite This Article: George Ch. Christoff, and Emilia G. Karova, "Characteristics of Sensitization to Inhalant and Food Allergens.” American Journal of Clinical Medicine Research, vol. 2, no. 3 (2014): 61-67. doi: 10.12691/ajcmr-2-3-3.

\section{Introduction}

The skin prick test (SPT) is a safe and easy to perform method for the assessment of specific sensitization to allergens. The main advantage of SPT is that the test can be interpreted within short time, it gives visualization of sensitivity and can be used to test less common allergens [12]. It is considered to be the test of choice in clinical practice and is usually supplemented by a spectrum of additional information obtained through the clinical history. SPT is also often used in epidemiologic studies in which the prevalence of sensitization to allergens is usually one of the main outcomes.

Many studies worldwide have reported prevalence of atopic sensitization. Regional variations in rates of sensitization to inhalant and food allergens have been shown in several large European and international studies $[2,20,24,25]$.

While the negative predictive value of a negative SPT is excellent for ruling out the presence of IgE-sensitization, a positive skin prick reaction, however, does not always correlate with clinical symptoms. A positive skin test reveals rather atopy - specific IgE presence, than an atopic disease itself. When combined clinical manifestation, medical history, optional further tests and SPT are a powerful instrument for defining allergic diseases. In that way clinical relevance of SPT is determined. Only few studies in small populations have investigated clinical relevance of SPT [8].

Monitoring the prevalence and patterns of IgE-mediated sensitization is important because skin prick test positivity is a significant risk factor for the development of atopic diseases [8]. When SPT is used as a common instrument, it is important to know what the predictive values are for subsequent tests. That in turn will help with patients' treatment indicating the predictive value of a single testing. In children, there is an association between the presence of atopy and the prevalence of asthma and rhinitis during childhood. Several studies have shown childhood asthma to be associated with sensitization to common allergens. Atopy is known to be a strong predictor both for asthma 
and rhinitis [1,16,22]. In regard to that it is of uttermost importance to collect data and analyze prevalence and patterns of sensitization to inhalant and food allergens not only in children but as well in general population. Such data for Bulgaria are however scarce.

Although there are some epidemiological studies on prevalence of allergic diseases, very little is known about prevalence of sensitization and its clinical relevance in Bulgaria.

The objective of the present study is to assess prevalence and patterns of sensitization to environmental and food allergens, its association with asthma and rhinitis and clinical relevance with regard to patient history in a cross-sectional community sample of the Bulgarian population.

\section{Materials and Methods}

\subsection{Study Design and Population}

The study is a cross-sectional investigation of 225 patients, men and women, median age of 34 years, range 4-81 years, consulting the outpatient allergy clinic of a major private hospital in Sofia, Bulgaria, because of a suspected IgE-mediated allergic disease. The study group consisted of 84 (37.3\%) men and 141 (62.7\%) women. Patients were divided in three age groups: $<18$ years - 38 (16.9\%); 19-44 years - $121(53.8 \%)$ and $>44$ years -64 (28.4\%).

\subsection{Methods}

The patients were referred by their primary care practitioner or it was their own decision to visit the department for an allergy checkup. The study was carried out in January-March 2011 parallel to the regular national census. All visits included an extensive questionnaire based interview (regarding atopic, heredity, medical history, and environmental factors), clinical examination by an allergist and skin prick testing.

\subsection{Questionnaire}

ISAAC [24] and ECRHS [25] questionnaires were modified to address the specific objectives of the study. The questionnaire had several sections directed to demographic, epidemiologic and economic data related to asthma and allergic rhinitis.

\subsection{Skin Prick Test}

Skin prick test (SPT) was performed according to the guidelines by the European Academy of Allergology and Clinical Immunology $[6,10,12]$.

The patients were tested with thirteen food allergens (milk, egg, pork, chicken, shrimp; sardine, celery, tomato, soy peach, apple, peanut, walnut) and fifteen inhalant allergens (birch mix, fagaceae mix, salicaceae mix, tree mix, 12 grass mix, 4 cereals, dog, cat, Dermatophagoides pteronyssinus, Dermatophagoides farinae, cockroach, alternaria mix, cladosporium mix, aspergillius mix, penicillium mix) using commercial allergen extracts (Alyostal Prick, Glycerinated allergen extracts dosed at 100IR-IC/mL Stallergenes, Antony, France and Cow milk prick $1000 \mathrm{BU} / \mathrm{ml}$ Bul Bio-NCIPD, Bulgaria). A positive
SPT was defined as a mean wheal diameter $\geq 3 \mathrm{~mm}$ larger than the negative control and controls showed adequate reactions. To assess degree of skin reactivity to tested allergens SPT results were graded on the basis of the ratio of the allergen wheal size to histamine wheal size in 5 levels: $3 \mathrm{~mm}>\mathrm{O}<0.7 ; 0.7 \geq \mathrm{A} \leq 1 ; 1>\mathrm{B} \leq 1.5 ; 1.5>\mathrm{C} \leq 2 ; \mathrm{D}>2$. SPT were defined as false negative when all tests and the positive control were negative; false positive - when all tests and the negative control were positive and there was no difference between the size of negative control wheal and these of the separate allergens.

\subsection{Definitions and Diagnostic Criteria}

Sensitization was defined by positive SPT to at least one allergen.

The clinical relevance of each of the positively tested allergens was assessed separately and subdivided into 3 distinct categories (no clinical relevance, clinical relevance, unknown relevance). This assessment was done by an experienced allergist according to patient history (type and season of symptoms).

Clinical relevance was stated if the patient`s prick test showed positive sensitization against the allergen in question and symptoms were reported if exposed to the same allergen. In case of pollen sensitization, particular attention was paid to the fact that symptoms had to occur in the corresponding flowering season of the respective plant.

No clinical relevance was stated if the patient`s prick test showed a positive sensitization against the allergen in question and no symptoms were reported if exposed to this particular allergen.

Unknown relevance was stated if the patient was unable to deny or confirm a positive prick test sensitization by reporting present or nonexistent symptoms during the respective allergen exposure. Unknown was, furthermore, stated if more than one sensitization could have been responsible for the symptoms reported.

Asthma was diagnosed if at least two or more of the following criteria were fulfilled according to the answers in the interview: (i) wheezing or whistling in the chest at any time in the past; (ii) wheezing in the chest in the past 12 months during or after exercise; (iii) dry cough at night, wheezing, shortage of breath in the past 12 months without having a cold.

Rhinitis was diagnosed if at least two or more of the following criteria were fulfilled according to the answers in the interview: (i) sneezing, runny, blocked nose, post nasal drip at any time in the past without flu or cold; (ii) sneezing, runny, blocked nose, post nasal drip in the past 12 months without flu or cold; (iii) seasonal and/or perennial occurrence of symptoms.

\subsection{Statistical Analysis}

Percentages (with SEs and 95\% CI) of the patients with positive skin test responses were estimated. Sociodemographic, medical examination variables and positive skin test responses were assessed as potential predictors of asthma and allergic rhinitis. Potential predictors were evaluated first with $\chi 2$ statistics and then with logistic regression. Only interactions significant at the 0.05 level were reported.

Statistical analyses were conducted with SPSS Version 19 (IBM® SPSS ${ }^{\circledR}$ Statistics). 


\section{Results}

\subsection{Prevalence}

Among 225 patients 129 (57.3\%) were sensitized to at least one allergen, using cut-off level $\geq 3 \mathrm{~mm}$. In 83 (36.9\%) patients no sensitization was found; 8 (3.6\%) patients had false negative SPT and 5 (2.2\%) - false positive.

Numbers of sensitisations per patient varied in wide range. In $1(0.4 \%)$ patient 23 sensitizations were found and in $18(8.0 \%)$ - 2 sensitizations. Most of the patients $49(21.8 \%)$ were sensitized to one, two or three allergens and other $36(16.0 \%)$ - to five, six or seven allergens at a time. Median number of positive responses was 9.0 (Table 1).

Proportions of positive skin prick tests in the study group ranged depending on cut-off levels. No difference was found between rates of sensitization if positive SPT levels A-D or O-D were used $(\mathrm{p}>0.1)$. In the inhalant allergens group the highest were rates of sensitization to 12 grasses - 26.6\% and 4 cereals - $24.0 \%$, followed by these to DFR - 18.2\%, DPT - 17.8\% and cockroach $16.4 \%$. Among food allergens the highest rates of sensitizations were found to pork - $16.9 \%$, walnut - $15.1 \%$, apple - $13.3 \%$, followed by egg whole, sardine and soy $10.7 \%$ each, celery $-9.8 \%$ and milk - 9.3\% (Table 2).
Table 1. Prevalence and number of sensitizations per patient

\begin{tabular}{|c|c|c|c|}
\hline \multirow{22}{*}{ 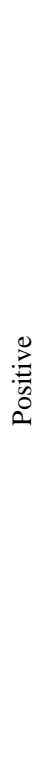 } & N sensitizations per patient & $\mathrm{N}$ & $\begin{array}{l}\text { Patients } \\
\% 95 \% \text { CI }\end{array}$ \\
\hline & Negative & 83 & 36.9 (30.543.3) \\
\hline & 1 & 16 & $7.1(3.7-10.5)$ \\
\hline & 2 & 18 & $8.0(4.4-11.8)$ \\
\hline & 3 & 15 & $6.7(3.4-10.0)$ \\
\hline & 4 & 5 & $2.2(0.3-4.1)$ \\
\hline & 5 & 13 & $5.8(2.3-8.3)$ \\
\hline & 6 & 10 & $4.4(1.7-7.1)$ \\
\hline & 7 & 13 & $5.8(2.7-8.9)$ \\
\hline & 8 & 8 & $3.6(1.1-6.1)$ \\
\hline & 9 & 8 & $3.6(1.1-6.1)$ \\
\hline & 10 & 9 & $4.0(1.4-6.9)$ \\
\hline & 11 & 4 & $1.8(0.04-3.6)$ \\
\hline & 12 & 4 & $1.8(0.04-3.6)$ \\
\hline & 15 & 1 & $0.4(-0.4-1.2)$ \\
\hline & 16 & 1 & $0.4(-0.4-1.2)$ \\
\hline & 18 & 2 & $0.9(-0.3-2.1)$ \\
\hline & 19 & 1 & $0.4(-0.4-1.2)$ \\
\hline & 23 & 1 & $0.4(-0.4-1.2)$ \\
\hline & Total & 129 & $573(50.8-63.8)$ \\
\hline & False(positive and negative) & 13 & $5.8(2.7-89)$ \\
\hline & Total & 225 & 100 \\
\hline
\end{tabular}

To compare the prevalence of sensitization to different allergens they were divided into several groups: indoor inhalant (DPT, DFR, cockroach, cat, and dog); indoor inhalant (moulds); outdoor inhalant (tree and grass pollen); food.

Table 2. Rates of sensitization to tested allergens depending on definition of positivity $(n=225)$

\begin{tabular}{|c|c|c|c|c|c|c|c|}
\hline \multirow{2}{*}{ Allergens } & \multicolumn{3}{|c|}{ Total(A-D) } & \multicolumn{3}{|c|}{ Total(0-D) } & \multirow[t]{2}{*}{$P$} \\
\hline & $\mathrm{N}$ & $\%$ & $95 \%$ CI & $\mathrm{N}$ & $\%$ & $95 \%$ CI & \\
\hline DPT & 36 & 16.0 & $11.2-20.8$ & 40 & 17.8 & $12.8-22.8$ & 0.6 \\
\hline DFR & 35 & 15.6 & $10.8-20.4$ & 41 & 182 & $13.1-232$ & 0.5 \\
\hline Cockroach & 31 & 13.8 & 9.3-18.3 & 37 & 16.4 & $11.5-213$ & 0.5 \\
\hline Cat & 32 & 142 & 9.6-18.8 & 35 & 15.6 & 10.6-20.0 & 0.7 \\
\hline Dog & 25 & 11.1 & $7.0-15.2$ & 27 & 12.0 & $7.7-16.3$ & 0.8 \\
\hline Cladosporium mix & 9 & 4.0 & $1.7-7.1$ & 11 & 4.9 & $2.1-7.7$ & 0.7 \\
\hline Alternaria & 10 & 4.4 & $2.1-7.7$ & 11 & 4.9 & $3.0-9.4$ & 0.8 \\
\hline Aspergillius mix & 11 & 49 & 1.4-6.6 & 14 & 6.2 & $2.1-7.7$ & 0.6 \\
\hline Penicillium mix & 21 & 93 & $5.5-13.1$ & 24 & 10.7 & $6.6-14.8$ & 0.6 \\
\hline 4 Cereak & 52 & 23.1 & $17.5-28.7$ & 54 & 24.0 & 18.4-29.6 & 0.8 \\
\hline 12 Grasses & 58 & 25.8 & $20.0-31.6$ & 59 & 262 & $20.4-32.0$ & 0.9 \\
\hline Fagaceae & 25 & 11.1 & $7.0-15.2$ & 31 & 13.8 & 93-18.3 & 0.4 \\
\hline Betubceae & 21 & 93 & $5.5-13.1$ & 25 & 11.1 & $7.0-15.2$ & 0.6 \\
\hline Saliraceae & 5 & 22 & $03-4.1$ & 6 & 2.7 & $0.7-4.8$ & 0.7 \\
\hline Tree Mix & 9 & 4.0 & 1.4-6.7 & 15 & 6.7 & $3.4-10.0$ & 0.2 \\
\hline Milk & 18 & 8.0 & $4.4-11.6$ & 21 & 9.3 & $5.5-13.1$ & 0.6 \\
\hline Egg Whole & 19 & 8.4 & $4.7-12.1$ & 24 & 10.7 & 6.6-14.8 & 0.4 \\
\hline Pork & 32 & 142 & 9.6-18.8 & 38 & 16.9 & $12.0-21.8$ & 0.5 \\
\hline Chicken & 18 & 8.0 & $4.4-11.6$ & 24 & 10.7 & $6.5-14.8$ & 0.4 \\
\hline Shrimp & 19 & 8.4 & 4.7-12.1 & 20 & 8.9 & 5.1-12.7 & 0.9 \\
\hline Sardina & 21 & 93 & $5.5-13.1$ & 24 & 10.7 & 6.6-14.8 & 0.6 \\
\hline Celery & 20 & 8.9 & $5.1-12.7$ & 22 & 9.8 & $5.9-13.7$ & 0.8 \\
\hline Tomato & 21 & 93 & 5.5-13.1 & 25 & 11.1 & $7.0-15.2$ & 0.6 \\
\hline Soy & 19 & 8.4 & $4.7-12.1$ & 24 & 10.7 & $6.6-14.8$ & 0.4 \\
\hline Peach & 17 & 7.6 & 4.1-11.1 & 21 & 9.3 & 5.5-13.1 & 0.5 \\
\hline Apple & 24 & 10.7 & $6.6-14.8$ & 30 & 133 & $8.8-17.8$ & 0.4 \\
\hline Peanut & 17 & 16 & 4.1-11.1 & 19 & 8.4 & $4.7-12.01$ & 0.8 \\
\hline Walnut & 31 & 13.8 & $9.3-18.3$ & 34 & 15.1 & $10.4-19.8$ & 0.7 \\
\hline
\end{tabular}

In the first indoor allergens group there was no difference in the sensitization rates $(p=0.4)$. In the pollen allergens group sensitization rates to grasses and cereals were higher than that to trees and sensitizations to Fagaceae and Betulaceae were higher than that to Tree mix $\left(p^{<}<0.001\right)$. Sensitization to Penicillium mix had the highest rate in the mould allergens group $(p=0.022)$. There was no difference in the sensitization rate to food allergens $(\mathrm{p}=0.080)$. 


\subsection{Clinical Relevance}

\subsubsection{Clinical Relevance by Allergens}

Clinically relevant were 249 (38\%) of all 656 positive SPT, with no clinical relevance - 268 (41\%) and 139 (21\%) positive SPT were with unknown clinical relevance.

In the inhalant allergens group the highest proportions of relevant tests out of all positive tests were for DPT $72.2 \%$, DFR - 62.9\%, 4 cereals - 69.2\%, 12 grasses - $69 \%$, Penicillium mix - 61.9\%, cockroach - 54.8\%, Betulaceae -
52.4\%. Among food allergens the highest proportions of relevant sensitization were found for walnut - 32.3\%, peanut $29.4 \%$, Milk - 22.2\%, egg whole - 21.1\%, soy 21.1\%, Apple - 20.8\%.

The highest proportions of SPT with no clinical relevance were for pork - 90,6\%, shrimp - 84,2\%, sardine - 81,0\%, chicken - 77,8\%, celery - 75,0\%, egg whole 73,7\%, milk - 72,2\%.

Proportions of unknown clinical relevance were the highest for dog - 92.0\%, cat - 78.1\%, tomato - 38.1\%, Betulaceae - 28.6\%, Fagaceae - 28.0\%. (Table 3, Figure 1)

Table 3. Clinical relevance of sensitization by allergens $(n=225)$

\begin{tabular}{|c|c|c|c|c|c|c|c|c|c|c|}
\hline \multirow{2}{*}{ Allergens } & \multicolumn{3}{|c|}{ Clinical relevance } & \multicolumn{3}{|c|}{ Unknown clinical relevance } & \multicolumn{3}{|c|}{ No clinical relebance } & \multirow{2}{*}{$\frac{\text { Total positive }}{\mathrm{N}}$} \\
\hline & $\mathrm{N}$ & $\%$ & $95 \%$ CI & $\mathrm{N}$ & $\%$ & $95 \%$ CI & $\mathrm{N}$ & $\%$ & $95 \%$ CI & \\
\hline DPT & 26 & 72.2 & $(66.3-78.1)$ & 4 & 11.1 & $(7.0-15.2)$ & 6 & 16.7 & $(11.8-21.6)$ & 36 \\
\hline DFR & 22 & 62.9 & $(56.5-69.3)$ & 1 & 2.9 & $(0.7-5.1)$ & 12 & 34.3 & $(28.0-40.6)$ & 35 \\
\hline Cockroach & 17 & 54.8 & $(48.2-61.3)$ & 4 & 12.9 & $(8.5-17.3)$ & 10 & 32.3 & $(26.1-38.5)$ & 31 \\
\hline Cat & 2 & 6.3 & $(3.1-9.5)$ & 25 & 78.1 & $(72.7-83.5)$ & 5 & 15.6 & $(10.8-20.4)$ & 32 \\
\hline Dog & 0 & 0.0 & & 23 & 92.0 & $(88.4-95.6)$ & 2 & 8.0 & $(4.4-11.8)$ & 25 \\
\hline Cladosporium mix & 3 & 30.0 & $(24.0-36.0)$ & 2 & 20.0 & $(14.7-25.3)$ & 5 & 50.0 & $(43.4-56.6)$ & 10 \\
\hline Alternaria & 5 & 45.5 & $(39.0-52.1)$ & 3 & 27.3 & $(21.4-33.2)$ & 3 & 27.3 & $(21.4-33.2)$ & 11 \\
\hline Aspergillius mix & 4 & 44.4 & $(37.9-51.0)$ & 2 & 22.2 & $(16.7-27.7)$ & 3 & 33.3 & $(27.1-39.5)$ & 9 \\
\hline Penicillium mix & 13 & 61.9 & $(56.0-68.3)$ & 4 & 19.0 & $(13.8-24.2)$ & 4 & 19.0 & $(13.8-24.2)$ & 21 \\
\hline 4 Cereak & 36 & 69.2 & (63.1-75.3) & 9 & 7.3 & $(12.3-22.3)$ & 7 & 13.5 & $(9.0-18.0)$ & 52 \\
\hline 12 Grasses & 40 & 69.0 & $(63.0-75.1)$ & 7 & 12.1 & $(7.8-16.4)$ & 11 & 19.0 & $(13.8-24.2)$ & 58 \\
\hline Fagaceae & 12 & 48.0 & $(41.4-54.6)$ & 7 & 28.0 & $(22.1-34.0)$ & 6 & 24.0 & $(18.4-29.6)$ & 25 \\
\hline Betubceae & 11 & 52.4 & $(45.8-59.0)$ & 6 & 28.6 & $(22.7-34.6)$ & 4 & 19.0 & $(13.8-24.2)$ & 21 \\
\hline Saliraceae & 4 & 80.0 & (74.7-85.3) & 0 & 0.0 & & 1 & 20.0 & $(14.7-25.3)$ & 5 \\
\hline Tree Mix & 7 & 77.8 & (72.3-83.3) & 1 & 11.1 & $(7.0-15.2)$ & 1 & 11.1 & (7.0-15.2) & 9 \\
\hline Milk & 4 & 22.2 & $(16.7-27.7)$ & 1 & 5.6 & $(2.6-8.6)$ & 13 & 72.2 & $(66.3-78.1)$ & 18 \\
\hline Egg Whole & 4 & 21.1 & $(15.7-26.3)$ & 1 & 5.3 & (2.3-8.3) & 14 & 73.7 & (68.0-79.5) & 19 \\
\hline Pork & 2 & 6.3 & $(3.1-9.5)$ & 1 & 3.1 & $(0.8-5.4)$ & 29 & 90.6 & $(86.7-94.4)$ & 21 \\
\hline Chicken & 4 & 22.2 & $(16.7-27.7)$ & 0 & 0.0 & & 14 & 77.8 & (72.3-83.3) & 18 \\
\hline Shrimp & 1 & 5.3 & $(2.3-8.3)$ & 2 & 10.5 & $(6.5-14.5)$ & 16 & 84.2 & $(79.4-89.0)$ & 19 \\
\hline Sardina & 3 & 14.3 & $(9.7-19.0)$ & 1 & 4.8 & $(2.0-7.6)$ & 17 & 81.0 & $(75.8-86.2)$ & 21 \\
\hline Celery & 2 & 10.0 & $(6.1-14.0)$ & 3 & 15.0 & $(10.3-19.7)$ & 15 & 75.0 & $(69.3-80.7)$ & 20 \\
\hline Tomato & 1 & 4.8 & $(2.0-7.6)$ & 8 & 38.1 & $(31.7-44.5)$ & 12 & 57.1 & (50.5-63-5) & 21 \\
\hline Soy & 4 & 21.1 & $(15.7-26.5)$ & 3 & 15.8 & $(11.0-20.6)$ & 12 & 63.2 & $(56.8-70.0)$ & 19 \\
\hline Peach & 2 & 11.8 & (7.6-16.1) & 5 & 29.4 & (23.4- 35.4) & 10 & 58.8 & (52.3-65.3) & 17 \\
\hline Apple & 5 & 20.8 & $(15.5-26.1)$ & 6 & 25.0 & $(19.3-30.7)$ & 13 & 54.2 & $(47.6-60.8)$ & 24 \\
\hline Peanut & 5 & 29.4 & $(23.4-35.4)$ & 4 & 23.5 & $(17.9-29.1)$ & 8 & 47.1 & $(40.5-53.7)$ & 17 \\
\hline Walnut & 10 & 32.3 & $(26.1-38.5)$ & 6 & 19.4 & $(14.2-24.6)$ & 15 & 48.4 & $(41.8-55.0)$ & 31 \\
\hline
\end{tabular}

In the group of clinically relevant SPT the allergen pattern was as follows: 12 grasses - 40 (16.1\%), 4 cereals 36 (14.5\%), DPT - 26 (10.4\%), DFR - 22 (8.8\%), cockroach - 17(6.8\%). The highest proportions in the group of positive SPT with unknown relevance were for cat - 25 (18.0\%) and dog - 23 (16.5\%). The highest proportions in the group with no clinical relevance were for pork - 29 (10.8\%), sardine - 17 (6.3\%), shrimp - 16 (6.0\%), walnut - 15 (5.6\%), celery - 15 (5.6\%), egg whole - 14 (5.2\%), chicken - 14 (5.2\%), milk - 13 (4.9\%).

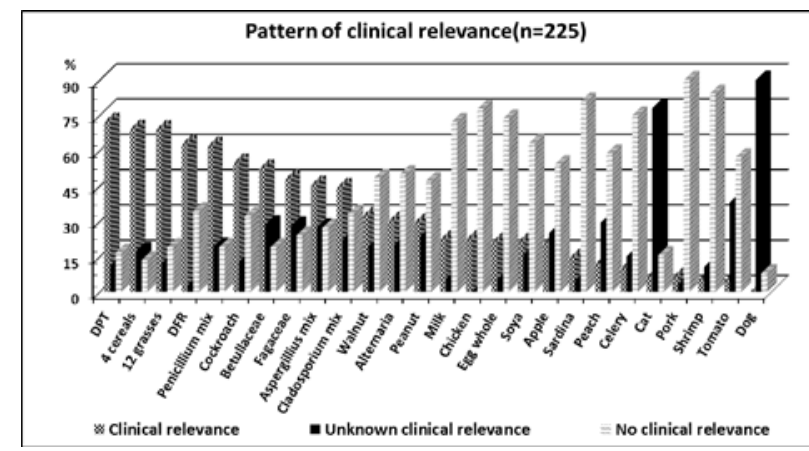

Figure 1. Pattern of clinical relevance by allergens

3.2.2. Clinical Relevance of Inhalant Allergens Sensitization in Patients with Allergic Rhinitis
Allergic rhinitis with medical history for tree pollen sensitization was clinically diagnosed in 5 patients. In 1 (20\%) of them positive SPT to Fagaceae and Betulaceae were present.

In 9 (50.0\%) out of 18 patients with allergic rhinitis and medical history for grass pollen sensitization positive SPT for 12 grasses and 4 cereals were found.

In 19 (70.4\%) out of 27 patients with medical history for grass and tree pollen sensitization, SPT positive to grass and tree allergens were found. Allergic rhinitis was diagnosed in 23 out of these 27 patients. In 17 (74.0\%) of the 23 patients with allergic rhinitis and medical history for grass and tree pollen sensitization there was at least one sensitization.

There were positive SPT for indoor and outdoor allergens in 18 (56.3\%) patients out of 32 with medical history for perennial sensitization with seasonal exacerbation. In 29 out these 32 patients allergic rhinitis was verified. There was at least one sensitization in 16 (55.2\%) out of the 29 patients with rhinitis and medical history for perennial and seasonal sensitization.

In $33(43.4 \%)$ out of 76 patients with medical history for perennial symptoms positive SPT to indoor/outdoor allergens were found. Only in 5, out of the 76 patients, rhinitis was verified and there was no sensitization in anyone of them. Rhinitis was not diagnosed in the 33 
patients with medical history for perennial sensitization and at least one positive SPT to indoor/outdoor allergens.

In patients with verified asthma and atopy proportion of clinically relevant sensitization was $65 \%$.

\subsection{Association between sensitization asthma, rhinitis and medical history for food allergy}

\subsubsection{Association between sensitization and asthma and rhinitis}

Sensitization was found in $72.7 \%$ of the participants defined as asthmatics.

The most frequent sensitization in asthmatics was that to 4 cereals - 35.7\%, followed by 12 grasses - 32.1\%, Apple - 30.4\%, DPT - 23.2\%, pork - 23.2\%, cat - 21.4\%, egg whole - $21.4 \%$, DFR - 21.4\%, cockroach - $19.6 \%$. The least frequent sensitization was to Cladosporium mix $3.6 \%$ (Table 4).

Table 4. Pattern of sensitization in asthmatics $(n=56)$

\begin{tabular}{|c|c|c|c|}
\hline & \multicolumn{3}{|c|}{ Patients } \\
\hline Allergen & $\mathrm{N}$ & $\%$ & $95 \%$ CI \\
\hline 4 cereals & 21 & 37.5 & (24.4-50.6) \\
\hline 12 grasses & 18 & 32.1 & $(19.3-44.2)$ \\
\hline Apple & 17 & 30.4 & $(18.0-42.8)$ \\
\hline DPT & 13 & 23.2 & $(11.8-34.6)$ \\
\hline Pork & 13 & 23.2 & $(11.8-34.6)$ \\
\hline$\overline{\text { DFR }}$ & 12 & 21.4 & $(10.3-32.5)$ \\
\hline Cat & 12 & 21.4 & $(10.3-32.5)$ \\
\hline Egg whole & 12 & 21.4 & $(10.3-32.5)$ \\
\hline Cockroach & 11 & 19.6 & $(8.9-30.3)$ \\
\hline Dog & 11 & 19.6 & $(8.9-30.3)$ \\
\hline Penicillium mix & 10 & 17.9 & $(7.5-28.3)$ \\
\hline Soya & 10 & 17.9 & $(7.5-28.3)$ \\
\hline Peanut & 10 & 17.9 & $(7.5-28.3)$ \\
\hline Walnut & 10 & 17.9 & $(7.5-28.3)$ \\
\hline Betullaceae & 9 & 16.1 & $(6.1-26.0)$ \\
\hline Peach & 9 & 16.1 & $(6.1-26.0)$ \\
\hline Fagaceae & 8 & 14.3 & $(4.8-23.8)$ \\
\hline Milk & 8 & 14.3 & $(4.8-23.8)$ \\
\hline Tomato & 8 & 14.3 & $(4.8-23.8)$ \\
\hline Aspergillius mix & 7 & 12.5 & $(3.6-21.4)$ \\
\hline Chicken & 7 & 12.5 & $(3.6-21.4)$ \\
\hline Sardina & 6 & 10.7 & $(2.3-19.1)$ \\
\hline Tree mix & 5 & 8.9 & $(1.2-16.6)$ \\
\hline Celery & 5 & 8.9 & $(1.2-16.6)$ \\
\hline Shrimp & 4 & 7.1 & $(0.2-14.0)$ \\
\hline Alternaria & 3 & 5.4 & $(-0.7-11.5)$ \\
\hline Salicaceae & 3 & 5.4 & $(-0.7-11.5)$ \\
\hline Cladosporium mix & 2 & 3.6 & $(-1.4-8.6)$ \\
\hline
\end{tabular}

The percentage of sensitization in non-asthmatics was significantly lower - 56, 7\% ( $p=0.025)$. There was no difference between mean number of sensitizations in asthmatics - 6.9 and non-asthmatics - 5.8 ( $\mathrm{p}=0.095)$ (Table 5).
Atopy is more frequent in patients with rhinitis than in these without rhinitis - $70.4 \%$ vs $55 \%$ ( $p=0.018$ ). No difference was found in the mean number of sensitizations in patients with and without rhinitis - 5.92 vs 5.88 respectively ( $p=0.067)$ (Table 5).

Table 5. Pattern of sensitization and number of sensitizations per patient with asthma and rhinitis $(n=212)$

\begin{tabular}{|c|c|c|c|c|c|c|}
\hline \multirow{2}{*}{} & \multicolumn{5}{|c|}{ Sensitization } \\
\cline { 2 - 6 } & $\begin{array}{c}\text { Negative } \\
\mathrm{n}(\%)\end{array}$ & $\begin{array}{c}\text { Positive } \\
\mathrm{n}(\%)\end{array}$ & Mean & SD & SE & P \\
\hline Asthma & $15(27.3)$ & $40(72.7)$ & 6.9 & 4.65 & 1.47 & \multirow{2}{*}{0.095} \\
\hline No asthma & $68(43.3)$ & $89(56.7)$ & 5.84 & 4.35 & 0.46 & \multirow{2}{*}{0.067} \\
\hline Rhinitis & $24(29.6)$ & $57(70.4)$ & 5.92 & 4.2 & 0.58 & \\
\hline No rhinitis & $59(45.0)$ & $72(55.0)$ & 5.88 & 4.33 & 0.51 & \\
\hline
\end{tabular}

Relative risk of sensitization as a predictor for asthma is 2.037 (1.040-3.99; $\mathrm{p}=0.038)$ and for rhinitis - 1.895 (1.043-3.445; $\mathrm{p}=0,036)$. Probability for rhinitis decreases with $60 \%$ after the age of 44 years - RR $0.394(\mathrm{p}=0.042)$. (Table 6 and Table 7)

Table 6. Age, sex and sensitization as predictors for asthma and rhinitis

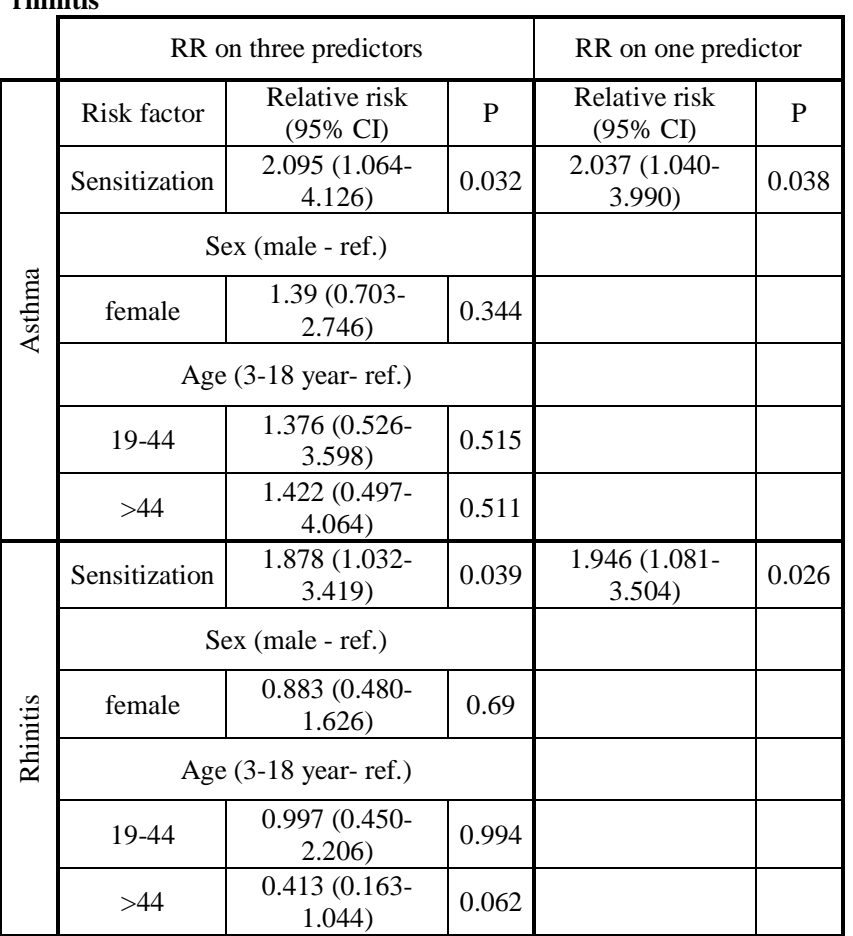

Table 7. Logistic regression: age and sensitization as risk factors for rhinitis

\begin{tabular}{|c|c|c|c|}
\hline & Risk factor & Relative risk (95\% CI) & $P$ \\
\hline \multirow{4}{*}{ 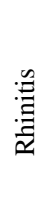 } & Sensitization & $1.895(1.043-3.445)$ & 0.036 \\
\hline & \multicolumn{3}{|c|}{ Age (3-18 year - ref.) } \\
\hline & $19-44$ & $0.952(0.445-2.038)$ & 0.899 \\
\hline & $>44$ & 0.394 (0.160-0.968) & 0.042 \\
\hline
\end{tabular}

\subsubsection{Association between sensitization and medical history for food allergy}

In 17 (35.4\%) out of 48 patients with medical history for food allergy at least one sensitization to food allergens was found. Just 4 (23.5\%) of these 17 were sensitized to the allergen revealed by their medical history (pork, walnut, egg, sardine) (Table 8). 
No association was found between history for food allergy and rate of sensitization to food allergens ( $p>0.05$ ).

Table 8. Sensitization and medical history for food allergy

\begin{tabular}{|c|c|c|c|c|}
\hline \multirow[b]{3}{*}{ Allergen } & \multirow[b]{3}{*}{ SPT } & \multirow{2}{*}{\multicolumn{2}{|c|}{$\begin{array}{c}\text { Medical history for food allergy } \\
\mathrm{n}(\%)\end{array}$}} & \multirow{3}{*}{$\mathrm{P}$} \\
\hline & & & & \\
\hline & & Yes $(n=48)$ & $\mathrm{No}(\mathrm{n}=177)$ & \\
\hline \multirow{3}{*}{ Milk } & $(+)$ & 6 (12.5) & $15(8.5)$ & 0.39 \\
\hline & $(-)$ & 39 (81.3) & 152 (85.9) & \\
\hline & invalid & $3(6.3)$ & $10(5.6)$ & \\
\hline \multirow{3}{*}{ Egg whole } & $(+)$ & $6(12.5)$ & $18(10.2)$ & 0.65 \\
\hline & $(-)$ & 39 (81.3) & $149(84.2)$ & \\
\hline & invalid & $3(6.3)$ & $10(5.6)$ & \\
\hline \multirow{3}{*}{ Pork } & $(+)$ & $5(10.4)$ & $33(18.6)$ & 0.18 \\
\hline & $(-)$ & 40 (83.3) & $134(75.7)$ & \\
\hline & invalid & $3(6.3)$ & $10(5.6)$ & \\
\hline \multirow{3}{*}{ Chiken } & $(+)$ & $5(10.4)$ & 19 (10.7) & 0.95 \\
\hline & $(-)$ & 40 (83.3) & 148 (83.6) & \\
\hline & invalid & $3(6.3)$ & $10(5.6)$ & \\
\hline \multirow{3}{*}{ Shrimp } & $(+)$ & $1(2.1)$ & 19 (10.7) & 0.06 \\
\hline & $(-)$ & 44 (91.7) & $148(83.6)$ & \\
\hline & invalid & $3(6.3)$ & $10(5.6)$ & \\
\hline \multirow{3}{*}{ Sardina } & $(+)$ & $3(6.3)$ & $21(11.9)$ & 0.27 \\
\hline & $(-)$ & 42 (87.5) & $146(82.5)$ & \\
\hline & invalid & $3(6.3)$ & $10(5.6)$ & \\
\hline \multirow{3}{*}{ Celery } & $(+)$ & $3(6.3)$ & 19 (10.7) & 0.36 \\
\hline & $(-)$ & $42(87.5)$ & $148(83.6)$ & \\
\hline & invalid & $3(6.3)$ & $10(5.6)$ & \\
\hline \multirow{3}{*}{ Tomato } & $(+)$ & - & 25 (14.1) & - \\
\hline & $(-)$ & 45 (93.8) & $142(80.2)$ & \\
\hline & invalid & $3(6.3)$ & $10(5.6)$ & \\
\hline \multirow{3}{*}{ Soy } & $(+)$ & $4(8.3)$ & $20(11.3)$ & 0.55 \\
\hline & $(-)$ & $41(85.4)$ & $147(83.1)$ & \\
\hline & invalid & $3(6.3)$ & $10(5.6)$ & \\
\hline \multirow{3}{*}{ Peach } & $(+)$ & $4(8.3)$ & $17(9.6)$ & 0.78 \\
\hline & $(-)$ & 41 (85.4) & $150(84.7)$ & \\
\hline & invalid & $3(6.3)$ & $10(5.6)$ & \\
\hline \multirow{3}{*}{ Apple } & $(+)$ & $5(10.4)$ & 25 (12.4) & 0.71 \\
\hline & $(-)$ & 40 (83.3) & $142(80.2)$ & \\
\hline & invalid & $3(6.3)$ & $10(5.6)$ & \\
\hline \multirow{3}{*}{ Peanut } & $(+)$ & $4(8.3)$ & $15(8.5)$ & 0.96 \\
\hline & $(-)$ & 41 (85.4) & $152(85.9)$ & \\
\hline & invalid & $3(6.3)$ & $10(5.6)$ & \\
\hline \multirow{3}{*}{ Walnut } & $(+)$ & $5(10.4)$ & 29 (16.4) & 0.30 \\
\hline & $(-)$ & $40(83.3)$ & $138(78.0)$ & \\
\hline & invalid & $3(6.3)$ & $10(5.6)$ & \\
\hline
\end{tabular}

\section{Discussion}

In a cross-sectional investigation of 225 patients, consulting an outpatient allergy clinic because of a suspected IgE-mediated allergic disease we evaluated prevalence of allergic sensitization to inhalant and food allergens. The overall rate of sensitization was high $57.3 \%$. Our data are consistent with findings in other studies on different population groups. Bousquet et al. found a global rate of sensitization to inhalant allergens $68.2 \%$ [7]. In another study the overall rate of sensitization was found to be $40.3 \%$ [4]. American study of sensitization rate in general population found that $54.3 \%$ of the population had positive test responses to at least one allergen [2]. In our study the percentage of the population with a positive test response decreased as the number of positive test responses increased from 1 to 23 . The pattern of number of sensitizations per patient is different from that found elsewhere - the highest being the prevalence of two positive responses $8.0 \%$ [2].

Variations of sensitization rates to inhalant allergens in Europe have been investigated in several large European studies such as the European Community Respiratory
Health Survey (ECRHS) [25], the International Study of Asthma and Allergies in Childhood (ISAAC) [24] and other multi-country studies [14,20]. Our study revealed the highest rates of sensitization to 12 grasses pollen allergens, 4 cereals, DFR, DPT and cockroach. It is difficult to compare these sensitization rates with data from other studies. We assume that they represent regional variations. The same pattern however is to be found in studies on population samples from different regions of Europe [8,13].

Clinical relevance of positive skin prick tests was assessed by an experienced allergist. We focused on detailed medical history data gathered in the course of the questionnaire based interview. The percentage of clinically relevant sensitizations was shown to depend on the allergen in question. Sensitizations to DPT, DFR, 4 cereals, 12 grasses, Penicillium mix, cockroach, and Betulaceae showed clinical relevance rates over 50\% whereas pork, shrimp, sardine, chicken, celery, egg whole and milk sensitizations had rates of no clinical relevance up to $90 \%$. Our data for rates and pattern of clinical relevance of sensitizations to inhalant allergens are in line with the findings from other European studies. They represent as well a regional variation $[8,13]$. The high proportions of unknown clinical relevance of sensitizations to dog and cat can be biased by the lack of particular questions about clinical reactions to cat and dog in the interview questionnaire. Proportions of unknown clinical relevance of sensitizations to Betulaceae and Fagaceae are probably due to the overlap of their pollination periods.

In our study we evaluated clinical relevance of sensitization to indoor and outdoor allergens in patients with allergic rhinitis. Proportions of symptomatic sensitization (allergic rhinitis) to grass pollen allergens, grass and tree pollen allergens, and pollen and indoor allergens were high - up to $74 \%$, whereas rates of symptomatic sensitization to tree allergens was relatively low - $20 \%$. Less than $50 \%$ of the patients with history for perennial symptoms were sensitized to indoor/outdoor allergens and in no one of them allergic rhinitis was verified. Less than $7 \%$ of the patients with perennial symptoms were diagnosed with allergic rhinitis and they were not sensitized to any perennial allergens. Symptomatic sensitization frequency is low in cases with medical history for rhinitis and tree pollen sensitization only, very high when anamnesis for rhinitis and sensitization to grass and tree pollen is available. We could not find any association between sensitization to perennial allergens and medical history for perennial allergic rhinitis.

Our findings for frequency of sensitization in patients with asthma and rhinitis show a considerably high rate of sensitization. It is rarer in patients without asthma and rhinitis. Our data are consistent with these from other studies [1,11,15,18].

Our data confirm the well-known fact that atopy is a strong risk factor for asthma and rhinitis [3,5,17,23]. We do not identify age and sex as risk factors. Probability for rhinitis decreases with $60 \%$ after the age of 44 years.

The findings of our study for sensitization to food allergens are interesting because they were obtained by SPT from an unselected predominantly adult population sample. They differ in some aspects from data by other 
studies in which serum specific IgE were used [9,19,21]. We found low rate of clinical relevance and lack of association between a self-reported food allergy and sensitization to food allergens.

\section{Conclusions}

In our study we find a high rate of overall sensitization which is in line with other European data. The pattern of sensitization prevalence for our study center is: 12 grasses at the top, followed by 4 cereals, DPT, DFR, cockroach, cat, dog. Our study demonstrates high rates of clinically relevant sensitizations to major inhalant allergen. The percentage of clinically relevant sensitizations differs significantly depending on the allergen.

The study demonstrates high rates of clinically relevant sensitizations to major inhalant allergen in asthmatics and patients with rhinitis.

\section{Acknowledgements}

The allergen extracts were provided free of charge by Stallergenes, Antony, France.

\section{References}

[1] Arbes SJ, Gergen PJ, Vaughn B, Zeldin DC. "Asthma cases attributable to atopy: results from the Third National Health and Nutrition Examination Survey”. J Allergy Clin Immunol. 120 (5): 1139-45, November 2007.

[2] Arbes, S J "Prevalences of positive skin test responses to10 common allergens in the US population: Results from the Third National Health and Nutrition Examination Survey.” J Allergy Clin Immunol, 116 (2): 377-83, August 2005.

[3] Arshad SH, Kurukulaaratchy RJ, Fenn M, Matthews S. "Early life risk factors for current wheeze, asthma, and bronchial hyperresponsiveness at 10 years of age.” Chest; 127 (2): 502-508. February 2005

[4] Blomme K1, Tomassen P, Lapeere H, Huvenne W, Bonny M, Acke F, Bachert C, Gevaert P. "Prevalence of allergic sensitization versus allergic rhinitis symptoms in an unselected population.” Int Arch Allergy Immunol, 160 (2): 200-7, January 2013.

[5] Bousquet J., Khaltaev N., Cruz A. A. et al. Allergic Rhinitis and its Impact on Asthma (ARIA). Allergy 63 (s86): 7-160, April 2008.

[6] Bousquet, J. et al. "Practical guide to skin prick tests in allergy to aeroallergens.” Allergy, 67 (1): 18-24 January 2012

[7] Bousquet, P.-J. et al. "GA2LEN skin test study III: Minimum battery of test inhalant allergens needed in epidemiological studies in patients.” Allergy 64 (11): 1656-1662, November 2009.

[8] Burbach, G. J. et al. "GA2LEN skin test study II: clinical relevance of inhalant allergen sensitizations in Europe." Allergy, 64 (11): 1507-1515, November, 2009.
[9] Burney PGJ, Potts J, Kummeling I, Mills ENC, Clausen M, Dubakiene R, Barreales L, Fernandez-Perez C, Fernandez-Rivas M, Le T-M, Knulst AC, Kowalski ML et al. "The prevalence and distribution of food sensitization in European adults.” Allergy, 69 (3): 365-37, March 2014.

[10] Eigenmann PA, Atanaskovic-Markovic M, O’B Hourihane J, et al. "Testing children for allergies: why, how, who and when." Pediatr Allergy Immunol 24 (2): 195-209, March 2013.

[11] Finnbogadottir AF, Ardal B, Eiriksson H, et al. "A long-term follow-up of allergic diseases in Iceland." Pediatr Allergy Immunol 23 (2): 181-5, March 2012.

[12] Heinzerling, L. et al. "The skin prick test-European standards." Clinical and Translational Allergy 3: 3, February 2013

[13] Heinzerling, L. M. et al, "GA2LEN skin test study I: GA2LEN harmonization of skin prick testing: novel sensitization patterns for inhalant allergens in Europe.” Allergy, 64 (10): 1498-1506, October 2009.

[14] Heinzerling, L. "Standard skin prick testing and sensitization to inhalant allergens. across Europe-a survey from the GA2LEN network.” Allergy 60 (10): 1287-1300, October 2005.

[15] Hoffmann-Petersen, B. et al. "Prevalence of IgE sensitization in Danish children with suspected asthma.” Pediatr Allergy Immunol, 24 (8): 727-733, December 2013.

[16] Lau S, Illi S, Sommerfeld C, et al. "Early exposure to house-dust mite and cat allergens and development of childhood asthma: a cohort study.” Multicentre Allergy Study Group. Lancet: 356 (9239): 1392-7, October 2000.

[17] Lazic1 N., Roberts G, Custovic, "A. Multiple atopy phenotypes and their associations with asthma: similar findings from two birth cohorts.” Allergy 68 (6): 764-70. June 2013.

[18] Nissen, S. P et al. "The natural course of sensitization and allergic diseases from childhood to adulthood." Pediatr Allergy Immunol, 24 (6): 540-548, September 2013.

[19] Nwaru, B. I. et al. "The epidemiology of food allergy in Europe: a systematic review and meta-analysi” s. Allergy 69 (1): 62-75, January 2014

[20] Ronchetti R, Haluszka J, Martella S, Falasca C, Guglielmi F, Parmiani S et al. "Skin reactivity to histamine and to allergens in unselected 9-year-old children living in Poland and Italy.” Pediatr Allergy Immunol 14 (3): 201-206, June 2003.

[21] Scott H. Sicherer, MD, and Hugh A. Sampson, MD. "Food allergy: Epidemiology, pathogenesis, diagnosis, and treatment.” J Allergy Clin Immunol 133 (2): 291-307 February 2014

[22] Sears MR, Greene JM, Willan AR, et al. "A longitudinal, population-based, cohort study of childhood asthma followed to adulthood.” N Engl J Med, 349 (15): 1414-22, October 2003.

[23] Sly PD, et al. "Early identification of atopy in the prediction of persistent asthma in children.” Lancet 372 (9643): 1100-1106. September 2008.

[24] Worldwide variation in prevalence of symptoms of asthma, allergic rhinoconjunctivitis, and atopic eczema: "ISAAC. The International Study of Asthma and Allergies in Childhood (ISAAC) Steering Committee.” Lancet 351 (9111): 1225-1232, April 1998.

[25] Zureik M, Neukirch C, Leynaert B, Liard R, Bousquet J, Neukirch F. "Sensitisation to airborne moulds and severity of asthma: cross sectional study from European Community respiratory health survey”. BMJ 325 (7361): 411-414, August 2002. 